\title{
Evaluation of Preoperative Short Course Intensity Modulated Radiation Therapy in Treatment of Locally Advanced Rectal Carcinoma
}

\author{
Ahmed EzzElregal ${ }^{1,}{ }^{*}$ MSc.;Mohsen Zikry ${ }^{1}$ MD;Magdy Salah Eldin ${ }^{2}$ MD;
} Khalid Elshahat ${ }^{1}$ PhD.

*Corresponding Author:

Ahmed

EzzElregalahmed_ezzelregal@az har.edu.eg

Received for publication June29, 2020; Accepted August25, 2020; Published onlineAugust 25, 2020.

Copyright 2020 The Authors published by Al-Azhar University, Faculty of Medicine, Cairo, Egypt. All rights reserved. This an open-access article distributed under the legal terms, where it is permissible to download and share the work provided it is properly cited. The work cannot be changed in anyway or used commercially.

doi:10.21608/aimj.2020.33474.1259

${ }^{1}$ Clinical oncology and nuclear medicine Department, Faculty of Medicine, Al-Azhar University, Cairo, Egypt.

${ }^{2}$ General surgery Department, Faculty of Medicine, Al-Azhar University, Cairo, Egypt.

\begin{abstract}
Background:The optimal RT fractionation and the timing of surgery in resectable locally advanced rectal carcinoma is still debatable. Postponing the time of surgery after SCRT seems to be more beneficial in inducing down-staging, and reducing postoperative morbidity than SCRT with immediate surgery. IMRT is used successfully in many cancers helping to achieve better conformality.

Aim of work: The study aimed to evaluate the efficacy and tolerability of preoperative short-course IMRT with delayed surgery in patients with resectable locally advanced rectal carcinoma.

Patient and Methods: Patients with resectable locally advanced rectal carcinoma were treated with preoperative short-course IMRT (25 Gy over 5 fractions) followed by surgery after 4-8 weeks.

Results: 37 patients were included, down-staging was observed in $54.1 \%$ of them; patients with cN2 disease, radiological EMVI, and radiologically involved mesorectalfacia (MRF) tend to have a statistically significant less down-staging. severe early and late toxicity was reported in $5.4 \%$ and $8.1 \%$ of the patients respectively, and $37 \%$ had postoperative complications. 33 patients (94.6\%) had curative surgery, 9\% had pCR, and sphincter sparing was achieved in $28 \%$ of patients with low rectal tumors. Cumulative 2 years DFS and OS were 71 $\%$ and $80 \%$ respectively.

Conclusion: SCRT with delayed surgery is a valid convenient, safe, and economically beneficial option in the treatment of locally advanced resectable rectal carcinoma, utilization of IMRT can help in reducing the dose to organs at risk. Further studies with a larger number of patients are mandatory to identify the most suitable patients for this approach.

Keywords:Resectable locally advanced rectal carcinoma; Shortcourse radiotherapy with delayed surger;IMRT.
\end{abstract}

Disclosure: The authors have no financial interest to declare in relation to the content of this article. The Article Processing Charge was paid for by the authors.

Authorship: All authors have a substantial contribution to the article.

\section{INTRODUCTION}

Neoadjuvant radiotherapy (RT) is frequently used in the treatment of locally advanced rectal carcinoma trying to achieve down-staging, sphincter preservation, as well as improvement in local control (LC) or even survival. ${ }^{1,2}$ There is still a debate on the optimal fractionation of RT, the timing of surgery, and the utilization of concurrent chemotherapy. ${ }^{3}$

Conventionally fractionated concurrent chemoradiotherapy (CCRT); (1.8-2 Gy ×25-28 fractions) followed by surgery after $4-8$ weeks is the most commonly used approach. ${ }^{(4-7)}$ This interval gives time for recovery from early toxicity and allows for down-staging, and achieving a pathological complete response (pCR). ${ }^{4,6,7,8,9,10}$
However, it increases morbidity, and, in some trials, mortality. ${ }^{\mathbf{1 1}, 12}$

Short-course radiotherapy (SCRT) with immediate surgery; 25 Gy over 5 fractions and surgery within the following week has been commonly used in Sweden and some other countries in Northern and Western Europe. ${ }^{4,5,6,7}$

Many trials have examined the most appropriate treatment schedule during the last 2 decades, Polish and Australian trials compared long-course CCRT with SCRT with immediate surgery, ${ }^{14,15}$ no significant differences were observed in postoperative complications, LC, late toxicity, or survival; nevertheless, a significantly lower acute radiation toxicity was observed with SCRT. 
Postponing the time of surgery after SCRT also seems to be beneficial in inducing down-staging, pCR, and reducing postoperative morbidity than SCRT with immediate surgery, however. it did not increase the rate of sphincter-saving procedures and curative surgery. ${ }^{16,17,18,19}$

Traditionally, pre-operative RT has been delivered via three-dimensional conformal RT (3DCRT) with three or four-field techniques for rectal cancer. More advanced techniques have been widely and successfully used for head-and-neck, prostate, and other cancers, such as intensity-modulated radiotherapy (IMRT), ${ }^{\mathbf{2 0} 21}$ however, its potential clinical benefits remain debatable in rectal cancer. ${ }^{22}$

The study aimed to evaluate the efficacy and tolerability of preoperative short-course IMRT with delayed surgery in patients with resectable locally advanced rectal carcinoma.

\section{PATIENTSAND METHODS}

The current work is a prospective study, including patients with a pathologically confirmed diagnosis of rectal carcinoma, in Clinical Oncology and Nuclear Medicine Department, El Hussein Hospital, Faculty of Medicine, Al-Azhar University during the period between June 2016 and August 2018. Approval of the ethical committee and written informed consent from every patient was obtained.

Eligibility criteria:

- Resectable locally advanced rectal adenocarcinoma; clinical stage II-III.

- Age more than 18 years and less than 80 of both genders.

- Performance Status $\leq 2$ ECOG scale.

- Ejection fraction $>55 \%$.

- Adequate laboratory investigations.

- Medically fit for surgery.

- Patients without any primary treatment for their current disease (surgical, chemotherapy, or radiotherapy).

Ineligibility Criteria:

- Tumors extending above $15 \mathrm{~cm}$ from the anal verge.

- Pregnant women.

- Patients with synchronous tumors of the colon.

- Patients with a history of malignancy except for basal cell carcinoma.

- Patients presented with intestinal obstruction.

- Obese patients (> $120 \mathrm{~kg}$ ).

- Severe skeletal deformity or any disease interfering with patient alignment and positioning for radiation therapy delivery.

All patients were subjected to clinical examination, colonoscopy, CT chest, abdomen and pelvis, Pelvic MRI with a series of laboratory investigations to assess the extent of disease and the presence of comorbidity if any.

Staging of the disease was assessed according to the AJCC cancer staging system the $7^{\text {th }}$ edition, ${ }^{23}$ and the
ECOG scale was used to assess the performance status. $^{24}$

Tumors were classified regarding the distance of the lower extent of the primary tumor from anal verge into:

High: $>10 \mathrm{~cm}$.

Middle: $>5 \mathrm{~cm}$ and $\leq 10 \mathrm{~cm}$.

Low: $\leq 5 \mathrm{~cm}$.

Mesorectalfacia (MRF) was considered involved when the distance of the tumor to the MRF of $\leqslant 1$ $\mathrm{mm}$.

Trial design:

In this prospective study, patients were planned to receive preoperative short course IMRT (25 Gy / 5 fractions in 5 consecutive days), then total mesorectal excision (TME) was planned 4-8 weeks after completion of neoadjuvant treatment. Target volumes and organs at risk were defined according to Radiationtherapy Oncology Group (RTOG) Consensus Panel Contouring Atlas. ${ }^{25,26}$

An IMRT plan designed to cover $98 \%$ of PTV with $95 \%$ of the treatment dose while delivering $105 \%$ of the treatment dose to below $10 \%$, and not delivering $\geq 110 \%$ of the treatment dose to the PTV. We kept the maximal irradiation dose of the bladder under 24 Gy, bowel under $25 \mathrm{~Gy}$, and femur heads under 20 Gy and kept the D50\% of the above 3 organs at risk (OARs), irradiated $\leq 20 \mathrm{~Gy}, \leq 13 \mathrm{~Gy}$, and $\leq 15$ Gy respectively.

Plans were generated concerning delivery using only 6-MV photons via linear accelerator (Varian Medical System). PTV coverage had been given the highest priority, then minimization of dose to bowel while the intermediate priority for reducing the dose to the bladder, and femoral head/neck. Quality assurance (QA) was done before starting treatment for every case, verification with an electronic portal image device (EPID) was done before every fraction.

Acute and late radiotherapy adverse effects were graded according to RTOG/EORTC radiation toxicity grading. ${ }^{27}$

Response evaluation:

Abdominopelvic CT, MRI pelvis and colonoscopy were done for all cases about one week before surgery. A tumor and/or nodal down-staging is considered when ycT and/or ycN is lower than cT and/or cN as defined by MRI, while clinical CR represented the absence of tumor by clinical examination, MRI, and colonoscopy.

Surgery:

TME (Total mesorectal excision) was planned 4-8 weeks after the completion of radiotherapy, and choice between low anterior resection and abdominoperineal resection and whether a temporary colostomy should be performed was left to the surgeon's discretion.

Surgery was considered adequate if achieving R0 resection (absence of macroscopic or microscopic 
residual disease), while pCR was considered when no malignant cells are observed in the surgical specimen.

Post-operative complications were the reported complication occurring within one month from surgery.

\section{Adjuvant treatment:}

Following wound healing, patients received six months of adjuvant chemotherapy either FOLFOX-4 regimen or Degramont regimen, the selection was based on the stage of the disease and the expected patient tolerance.

Follow up:

After finishing adjuvant chemotherapy regimen patients had scheduled visits with investigations (CEA every 3 months, CT scan every 6 months, and colonoscopy in 1 year, then every $2-3$ years if negative).

Disease-free survival (DFS) was the time from surgery to confirmed local recurrence, distant metastases, or death whichever occurred first, patients who neither relapsed nor died were censored at last assessment before a loss to follow-up.

Overall survival was the time from diagnosis till death, with survivors being censored at the time of the last follow-up. Living patients or patients lost to follow-up were censored on the last known alive date.

\section{Statistical Methods:}

Statistical presentation and analysis of this study were conducted via SPSS V22, using the mean, standard deviation, student t-test, chi-square, linear correlation coefficient, and analysis of variance [ANOVA] tests, survival analysis was done using Kaplan-Meier method, and the p-value was considered significant if $\leq 0.05$.

\section{RESULTS}

The current prospective study included 37 patients with a pathologically confirmed diagnosis of locally advanced resectable rectal adenocarcinoma fulfilling the eligibility criteria. Table (1) demonstrates the clinicopathologic features of the patients.

The whole study group received preoperative IMRT 25 Gy / 5 fractions over 5 consecutive days without any interruptions. PTV coverage, doses received by OAR, homogeneity index, and conformity index are shown in table (2)

Down-staging was observed in 20 patients (54.1\%); it was noticed that 4 patients (10.8\%) had a clinical CR, 16 patients (43.2\%) had a partial response (PR), 15 patients (40.5\%) had stable disease (SD) while 2 patients $(5.4 \%)$ had disease progression (PD). Factors affecting clinical down-staging are shown in table (3).

It was noticed that patients with cN2 disease, radiological EMVI, and radiologically involved mesorectalfacia (MRF) tend to have a poor clinical response with statistically significant $P$-values.

Only 35 patients (94.6\%) submitted to surgery while one patient $(2.7 \%)$ refused surgery as she achieved clinical CR and the other one (2.7\%) was unfit for surgery.

The median period between radiotherapy and surgery was 7.3 weeks (range of 4.3-8 weeks), Curative surgery was done in 33 patients (94.3\%) only; 17 of them (51.5\%) had an anterior resection and the remaining 16 patients (48.5\%) had APR. On the contrary, 2 patients had laparotomy only but the tumor was found to be irresectable. For patients having low rectal tumors at presentation (25 patients), sphincter sparing was successfully achieved in 7 of them (28\%)

Histopathological examination and pathological TNM staging were done; histopathology evaluation results are shown in table (4).

All the 33 patients who submitted to curative surgery received adjuvant chemotherapy; 26 patients $(78.8 \%)$ received the FOLFOX-4 regimen while 7 patients (21.2\%) received the Degramont regimen, which was given to patients who experienced pCR and patients who were not expected to tolerate FOLFOX-4 regimen.

Most of the patients tolerated radiotherapy well, as no patients suffered from grade III or IV hematological toxicity, and no grade IV nonhematological toxicity was reported.

Only two patients (5.4\%) had grade III early skin toxicity with no reported late skin effects, no patients suffered from GIII early bowel or bladder toxicity on the contrary GIII late bowel and bladder toxicity was reported in $5.4 \%$ and $2.7 \%$ respectively, table (5).

Surgical complications were reported in $37 \%$ $(13 / 35)$ of the operated patients, wound infection was the most frequently reported surgical complication and it occurred in $14.2 \%(5 / 35)$ of the patients; three of them (60\%) were submitted to APR, the next most frequent complication was delayed wound healing and it was reported in $11.4 \%$ (4/35) of the patients; three of them (75\%) also were submitted to APR, table (6).

Only 33 patients who submitted to R0 resection were evaluated for PFS and OS; The median follow up period was 23 months, by the end of this study, 6 patients (18.2\%) died and 27 patients (81.8\%) were still alive.

$9 \%$ of the patients (3/33) suffered from a locoregional recurrence, $21.2 \%$ (7/33) had distant metastasis while $6 \%(2 / 33)$ had simultaneous systemic and locoregional recurrences.

The liver was the common partner in all cases with distant metastasis as it was reported in all the seven patients $(100 \%)$ with distant metastasis, then lung, para-aortic lymph nodes and bone with 2 cases 
(28.6\%) for each of them and the lowest was the skin which was present only in one patient (14.3\%).

\begin{tabular}{|c|c|c|c|}
\hline \multirow{4}{*}{ Age } & \multirow{4}{*}{$\begin{array}{c}\text { Range } \\
\text { Mean } \pm \text { SD }\end{array}$} & \multicolumn{2}{|c|}{$22-72$} \\
\hline & & & \\
\hline & & & \\
\hline & & $\mathbf{N}(37)$ & $\%$ \\
\hline \multirow{2}{*}{ Age group } & $<40$ Years & 10 & 27.00 \\
\hline & $\geq 40$ Years & 27 & 73.00 \\
\hline \multirow{2}{*}{ Gender } & Male & 20 & 54.05 \\
\hline & Female & 17 & 45.95 \\
\hline \multirow{2}{*}{ Family history } & positive & 3 & 8.11 \\
\hline & negative & 34 & 91.89 \\
\hline \multirow{4}{*}{ Comorbidity } & HTN & 7 & 18.92 \\
\hline & $\mathrm{DM}$ & 7 & 18.92 \\
\hline & HCV positive & 3 & 8.11 \\
\hline & COPD & 2 & 5.41 \\
\hline \multirow{2}{*}{ Smoking } & Smokers & 7 & 18.92 \\
\hline & Non smokers & 30 & 81.08 \\
\hline \multirow{3}{*}{ Performance Status } & 0 & 3 & 8.11 \\
\hline & $\mathrm{I}$ & 24 & 64.86 \\
\hline & II & 10 & 27.03 \\
\hline \multirow{5}{*}{ Clinical presentation } & Bleeding per rectum & 34 & 91.89 \\
\hline & Constipation & 18 & 48.65 \\
\hline & Pelvic pain & 18 & 48.65 \\
\hline & Change of bowel habits & 10 & 27.03 \\
\hline & Loss of weight & 7 & 18.92 \\
\hline \multirow{2}{*}{ Initial Tumor marker } & High & 34 & 91.89 \\
\hline & Normal & 3 & 8.11 \\
\hline \multirow{3}{*}{ Tumor Site } & Low & 25 & 67.57 \\
\hline & Middle & 8 & 21.62 \\
\hline & High & 4 & 10.81 \\
\hline \multirow{4}{*}{ Histopathology } & Adenocarcinoma & 30 & 81.08 \\
\hline & Mucinous & 4 & 10.81 \\
\hline & Signet ring & 2 & 5.41 \\
\hline & Undifferentiated carcinoma & 1 & 2.70 \\
\hline \multirow{4}{*}{ Grade } & I & 3 & 8.11 \\
\hline & II & 22 & 59.46 \\
\hline & III & 11 & 29.73 \\
\hline & IV & 1 & 2.70 \\
\hline \multirow{3}{*}{$\begin{array}{l}\text { Pretreatment clinical tumor } \\
\text { staging(cT) }\end{array}$} & 2 & 9 & 24.32 \\
\hline & 3 & 26 & 70.27 \\
\hline & 4 & 2 & 5.41 \\
\hline \multirow{5}{*}{$\begin{array}{c}\text { Pretreatment clinical nodal } \\
\text { staging(cN) }\end{array}$} & 0 & 4 & 10.81 \\
\hline & $1 \mathrm{a}$ & 6 & 16.22 \\
\hline & $1 \mathrm{~b}$ & 16 & 43.24 \\
\hline & 2a & 4 & 10.81 \\
\hline & $2 \mathrm{~b}$ & 7 & 18.92 \\
\hline \multirow{3}{*}{ Pretreatment clinical stage group } & IIA & 4 & 10.81 \\
\hline & IIIA & 8 & 21.62 \\
\hline & IIIB & 19 & 51.35 \\
\hline \multirow{2}{*}{$\begin{array}{c}\text { Radiological Extramural vascular } \\
\text { invasion (EMVI) }\end{array}$} & Yes & 7 & 18.92 \\
\hline & No & 30 & 81.08 \\
\hline \multirow{2}{*}{$\begin{array}{l}\text { Radiological mesorectal fascia } \\
\text { (MRF) involvement }\end{array}$} & Positive & 6 & 16.22 \\
\hline & Negative & 31 & 83.78 \\
\hline
\end{tabular}

Table 1: The clinicopathologic characteristics of the study group. 


\begin{tabular}{|c|c|c|}
\hline \multirow{2}{*}{\multicolumn{2}{|c|}{ Parameter }} & Value \\
\hline & & Mean \pm SD \\
\hline \multicolumn{2}{|c|}{ PTV volume } & $1588 \pm 277$ cC \\
\hline \multicolumn{2}{|c|}{ PTV mean dose } & $25.45 \pm 0.19$ \\
\hline \multicolumn{2}{|c|}{ Dmax (Gy) } & $26.57 \pm 0.29$ \\
\hline \multicolumn{2}{|c|}{ Dmin (Gy) } & $20.6 \pm 1.47$ \\
\hline \multicolumn{2}{|c|}{ D98\% } & $24.49 \pm 0.22 \mathrm{~Gy}$ \\
\hline \multicolumn{2}{|c|}{ D50\% } & $25.49 \pm 0.21 \mathrm{~Gy}$ \\
\hline \multicolumn{2}{|c|}{ D2\% } & $26 \pm 0.23 \mathrm{~Gy}$ \\
\hline \multicolumn{2}{|c|}{ HI } & $0.059 \pm 0.01$ \\
\hline \multicolumn{2}{|c|}{ CI } & $0.98 \pm 0.04$ \\
\hline \multicolumn{2}{|c|}{ Bowel volume } & $947.46 \pm 320.41 \mathrm{cc}$ \\
\hline \multicolumn{2}{|c|}{ Bowel mean dose } & $11.31 \pm 1.79$ Gy \\
\hline \multirow{2}{*}{ Bowel V25 Gy } & Volume (cc) & $15.50 \pm 25.22$ \\
\hline & Percentage (\%) & $1.450 \% \pm 2.732$ \\
\hline \multirow{2}{*}{ Bowel V22.5 Gy } & Volume (cc) & $66.98 \pm 62.25$ \\
\hline & Percentage \% & $6.890 \% \pm 5.722$ \\
\hline \multirow{2}{*}{ Bowel V20 Gy } & Volume (cc) & $118.64 \pm 82.11$ \\
\hline & Percentage $\%$ & $12.259 \% \pm 6.937$ \\
\hline \multirow{2}{*}{ Bowel V17 Gy } & Volume (cc) & $193.80 \pm 115.40$ \\
\hline & Percentage \% & $19.870 \% \pm 8.733$ \\
\hline \multirow{2}{*}{ Bowel V15 Gy } & Volume (cc) & $263.24 \pm 143.32$ \\
\hline & Percentage \% & $27.373 \% \pm 10.916$ \\
\hline \multirow{2}{*}{ Bowel V10 Gy } & Volume (cc) & $508.70 \pm 180.59$ \\
\hline & Percentage $\%$ & $54.054 \% \pm 11.352$ \\
\hline \multirow{2}{*}{ Bowel V5 Gy } & Volume (cc) & $714.34 \pm 234.74$ \\
\hline & Percentage \% & $76.173 \% \pm 8.600$ \\
\hline \multicolumn{2}{|c|}{ Urinary bladder volume } & $278.47 \pm 232.84 \mathrm{cc}$ \\
\hline \multicolumn{2}{|c|}{ Urinary bladder mean dose } & $20.5 \pm 2.4 \mathrm{~Gy}$ \\
\hline \multicolumn{2}{|c|}{ Rt. Femoral head mean dose } & $10.67 \pm 1$ Gy \\
\hline \multicolumn{2}{|c|}{ Lt. Femoral head mean dose } & $10.55 \pm 1.14 \mathrm{~Gy}$ \\
\hline \multicolumn{2}{|c|}{ Bone marrow volume } & $1374 \pm 178.2$ сc \\
\hline \multicolumn{2}{|c|}{ Bone marrow mean dose } & $13.63 \pm 1.6 \mathrm{~Gy}$ \\
\hline
\end{tabular}

Table 2: Radiotherapy parameters. 


\begin{tabular}{|c|c|c|c|c|c|c|c|c|c|}
\hline & & \multirow{2}{*}{\multicolumn{6}{|c|}{ Clinical down staging }} & \multirow{3}{*}{\multicolumn{2}{|c|}{ T-Test }} \\
\hline & & & & & & & & & \\
\hline & & \multirow{2}{*}{\multicolumn{3}{|c|}{$\begin{array}{c}\text { Yes } \\
\text { Mean } \pm \text { SD }\end{array}$}} & \multirow{2}{*}{\multicolumn{3}{|c|}{$\begin{array}{c}\text { No } \\
\text { Mean } \pm \text { SD }\end{array}$}} & & \\
\hline & & & & & & & & $\mathbf{t}$ & P-value \\
\hline \multicolumn{2}{|l|}{ Age } & \multicolumn{3}{|c|}{$50.450 \pm 13.694$} & \multicolumn{3}{|c|}{$48.000 \pm 16.647$} & 0.491 & 0.626 \\
\hline Duration of Symptoms (Months) & & \multicolumn{3}{|c|}{$3.450 \pm 2.523$} & \multicolumn{3}{|c|}{$4.382 \pm 3.257$} & -0.981 & 0.333 \\
\hline Period from diagnosis to RT (Days) & & \multicolumn{3}{|c|}{$11.200 \pm 3.286$} & \multicolumn{3}{|c|}{$13.412 \pm 6.847$} & -1.283 & 0.208 \\
\hline \multirow[t]{4}{*}{ Period from radiotherapy to surgery (Weeks) } & & \multicolumn{3}{|c|}{$7.078 \pm 1.048$} & \multicolumn{3}{|c|}{$6.929 \pm 0.905$} & 0.447 & 0.658 \\
\hline & & \multicolumn{6}{|c|}{ Clinical down staging } & \multirow{2}{*}{\multicolumn{2}{|c|}{ Chi-Square }} \\
\hline & & \multicolumn{2}{|r|}{ Yes } & \multicolumn{2}{|c|}{ No } & \multicolumn{2}{|c|}{ Total } & & \\
\hline & & $\overline{\mathbf{N}}$ & $\%$ & $\mathbf{N}$ & $\%$ & $\mathbf{N}$ & $\%$ & $\overline{X^{2}}$ & P-value \\
\hline A qe qroun & $<<40$ Years & 5 & 25.00 & 5 & 29.41 & 10 & 27.03 & & \\
\hline Age group & $\geq 40$ Years & 15 & 75.00 & 12 & 70.59 & 27 & 72.97 & 0.091 & 0.763 \\
\hline & Male & 11 & 55.00 & 9 & 52.94 & 20 & 54.05 & & \\
\hline Sex & Female & 9 & 45.00 & 8 & 47.06 & 17 & 45.95 & 0.016 & 0.900 \\
\hline & Yes & 0 & 0.00 & 3 & 17.65 & 3 & 8.11 & & \\
\hline Family history & No & 20 & 100.00 & 14 & 82.35 & 34 & 91.89 & 1.837 & 0.175 \\
\hline & Yes & 4 & 20.00 & 3 & 17.65 & 7 & 18.92 & & \\
\hline Smoking & No & 16 & 80.00 & 14 & 82.35 & 30 & 81.08 & 0.033 & 0.855 \\
\hline & 0 & 2 & 10.00 & 1 & 5.88 & 3 & 8.11 & & \\
\hline Performance Status & $\mathrm{I}$ & 14 & 70.00 & 10 & 58.82 & 24 & 64.86 & 1.164 & 0.559 \\
\hline & II & 4 & 20.00 & 6 & 35.29 & 10 & 27.03 & & \\
\hline & High & 19 & 95.00 & 15 & 88.24 & 34 & 91.89 & & \\
\hline Initial Tumor marker & Normal & 1 & 5.00 & 2 & 11.76 & 3 & 8.11 & 0.564 & 0.452 \\
\hline & High & 1 & 25.00 & 3 & 75.00 & 4 & 10.81 & & \\
\hline Tumor site & middle & 3 & 37.50 & 5 & 62.50 & 8 & 21.62 & 2.954 & 0.184 \\
\hline & Low & 16 & 64 & 9 & 36 & 25 & 67.57 & & \\
\hline & Adeno & 18 & 90.00 & 12 & 70.59 & 30 & 81.08 & & \\
\hline Histonatholooy & Mucinous & 0 & 0.00 & 4 & 23.53 & 4 & 10.81 & 5996 & 0112 \\
\hline Histopathology & Signet ring & 1 & 5.00 & 1 & 5.88 & 2 & 5.41 & 5.996 & 0.112 \\
\hline & Undifferentiated & 1 & 5.00 & 0 & 0.00 & 1 & 2.70 & & \\
\hline & $\mathrm{I}$ & 2 & 10.00 & 1 & 5.88 & 3 & 8.11 & & \\
\hline Grade & II & 12 & 60.00 & 10 & 58.82 & 22 & 59.46 & 1372 & 0712 \\
\hline Grade & III & 5 & 25.00 & 6 & 35.29 & 11 & 29.73 & 1.372 & 0.712 \\
\hline & IV & 1 & 5.00 & 0 & 0.00 & 1 & 2.70 & & \\
\hline & $\mathrm{T} 2$ & 3 & 15.00 & 6 & 35.29 & 9 & 24.32 & & \\
\hline Pretreatment clinical tumor staging(cT) & T3 & 17 & 85.00 & 9 & 52.94 & 26 & 70.27 & 5.253 & 0.072 \\
\hline & $\mathrm{T} 4$ & 0 & 0.00 & 2 & 11.76 & 2 & 5.41 & & \\
\hline & N0-1 & 17 & 85.00 & 9 & 52.94 & 26 & 70.27 & 4521 & $0033 *$ \\
\hline Pretreatment clinical nodal staging(cN) & $\mathrm{N} 2$ & 3 & 15.00 & 8 & 47.06 & 11 & 29.73 & 4.521 & $0.033^{*}$ \\
\hline & IIA & 4 & 20.00 & 0 & 0.00 & 4 & 10.81 & & \\
\hline & IIIA & 4 & 20.00 & 4 & 23.53 & 8 & 21.62 & & \\
\hline Pretreatment clinical stage group & IIIB & 11 & 55.00 & 8 & 47.06 & 19 & 51.35 & 6.943 & 0.074 \\
\hline & IIIC & 1 & 5.00 & 5 & 29.41 & 6 & 16.22 & & \\
\hline & Yes & 1 & 5.00 & 6 & 35.29 & 7 & 18.92 & & $0019 *$ \\
\hline Radiological Extramural vascular invasion (EMVI) & No & 19 & 95.00 & 11 & 64.71 & 30 & 81.08 & 5.498 & $0.019 *$ \\
\hline & Positive & 1 & 5.00 & 5 & 29.41 & 6 & 16.22 & & \\
\hline Radiological mesorectal fascia (MRF) involvement & Negative & 19 & 95.00 & 12 & 70.59 & 31 & 83.78 & 4.031 & $0.045^{*}$ \\
\hline
\end{tabular}

Table 3: Factors affecting clinical down staging: 
Histopathology

Grade

Pathological primary tumor assessment (ypT)

Pathological nodal assessment (ypN)

\begin{tabular}{|c|c|c|}
\hline & N (35) & $\%$ \\
\hline Adenocarcinoma & 28 & 80 \\
\hline Mucinous & 4 & 11.4 \\
\hline Signet ring & 2 & 5.7 \\
\hline Undifferentiated carcinoma & 1 & 2.9 \\
\hline I & 3 & 8.6 \\
\hline II & 21 & 60 \\
\hline III & 10 & 28.6 \\
\hline IV & 1 & 2.9 \\
\hline T0 & 3 & 8.57 \\
\hline $\mathrm{T} 1$ & 1 & 2.86 \\
\hline $\mathrm{T} 2$ & 15 & 42.86 \\
\hline T3 & 14 & 40.00 \\
\hline $\mathrm{T} 4$ & 2 & 5.71 \\
\hline No & 10 & 28.57 \\
\hline $1 \mathrm{a}$ & 6 & 17.14 \\
\hline $1 \mathrm{~b}$ & 8 & 22.86 \\
\hline $2 \mathrm{a}$ & 3 & 8.57 \\
\hline $2 \mathrm{~b}$ & 8 & 22.86 \\
\hline pCR & 3 & 8.57 \\
\hline $\mathrm{I}$ & 5 & 14.29 \\
\hline IIA & 2 & 5.71 \\
\hline IIIA & 9 & 25.71 \\
\hline IIIB & 8 & 22.86 \\
\hline IIIC & 8 & 22.86 \\
\hline Yes & 5 & 14.3 \\
\hline No & 30 & 85.7 \\
\hline Yes & 4 & 11.4 \\
\hline No & 31 & 88.6 \\
\hline Complete necrosis & 3 & 8.57 \\
\hline Partial necrosis & 23 & 65.71 \\
\hline No Necrosis & 9 & 25.71 \\
\hline
\end{tabular}

Table 4: Histopathology evaluation results.

\begin{tabular}{|c|c|c|c|c|c|c|}
\hline \multicolumn{2}{|c|}{ Toxicity } & G I & G II & G III & G IV & G V \\
\hline \multicolumn{7}{|c|}{ Hematological } \\
\hline \multicolumn{2}{|c|}{ Anemia } & 1(2.7\%) & $2(5.4 \%)$ & 0 & 0 & 0 \\
\hline \multicolumn{2}{|c|}{$\begin{array}{c}\text { Neutropenia } \\
\end{array}$} & $3(8.1 \%)$ & $1(2.7 \%)$ & 0 & 0 & 0 \\
\hline \multicolumn{2}{|c|}{ Thrombocytopenia } & 0 & 0 & 0 & 0 & 0 \\
\hline \multicolumn{7}{|c|}{ Non-hematological } \\
\hline \multirow{2}{*}{ Skin } & Early & 19(51.35\%) & $6(16.22 \%)$ & $2(5.4 \%)$ & 0 & 0 \\
\hline & Late & 0 & 0 & 0 & 0 & 0 \\
\hline \multirow{2}{*}{ Bowel } & Early & 13(35.14\%) & $3(8.11 \%)$ & 0 & 0 & 0 \\
\hline & Late & $4(10.81 \%)$ & 0 & $2(5.4 \%)$ & 0 & 0 \\
\hline \multirow{2}{*}{ Bladder } & Early & 14(37.84\%) & $1(2.70 \%)$ & 0 & 0 & 0 \\
\hline & Late & $2(5.41 \%)$ & $1(2.70 \%)$ & $1(2.7 \%)$ & 0 & 0 \\
\hline
\end{tabular}


Table 5: Neoadjuvant RT related toxicity.

\begin{tabular}{||l|c|c|}
\hline \multicolumn{1}{|c|}{ Surgical complications } & Number & Percentage \\
\hline \hline Delayed wound healing & 4 & $11.4 \%$ \\
\hline wound infection & 5 & $14.2 \%$ \\
\hline Urinary bladder injury & 1 & $2.86 \%$ \\
\hline Fistula & 1 & $2.86 \%$ \\
\hline DVT & 1 & $2.86 \%$ \\
\hline Abdominal dehiscence & 1 & $2.86 \%$ \\
\hline
\end{tabular}

Table 6: Surgical complications.

The median DFS and OS have not been reached. The cumulative 1 year and 2 years DFS were $88 \%$ and $71 \%$ respectively, while the cumulative 1 year and 2 years OS were $90.1 \%$ and $80 \%$ respectively, Figures (1\&2).

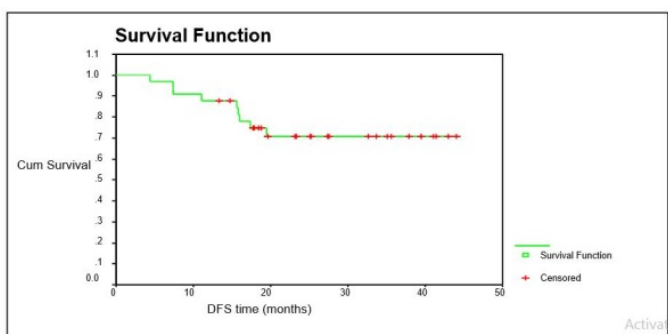

Fig. 1: Disease free survival.

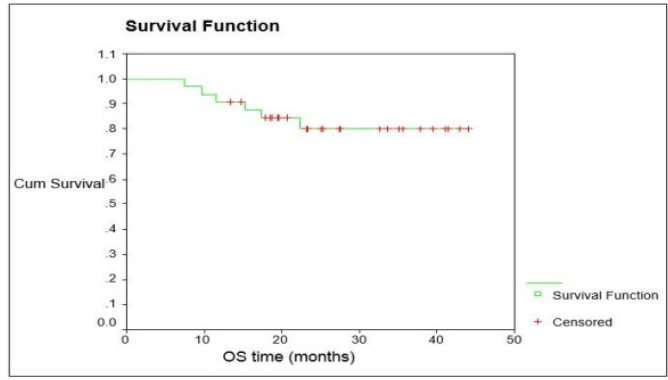

Fig. 2: Overall survival.

Factors affecting DFS and overall survival were studied, (Table 7,8). It was found that patients younger than 40 years old and patients with ypN2 stage have significantly worse PFS but there was no significant impact on OS, on the other hand, other prognostic variables Showed no statistically significant effect on either PFS or OS.

\section{DISCUSSION}

The optimal RT fractionation, concomitant chemotherapy, and the proper timing of surgery in patients suffering from locally advanced resectable rectal carcinoma has been much debated.

The general idea of the current prospective study was to explore the safety of SCRT with delayed surgery and its efficacy to induce Down-staging, pCR, sphincter preservation, and the impact of utilizing IMRT in reducing the dose to OAR.

SCRT followed by immediate surgery, doesn't induce down-staging, ${ }^{(28)}$ but a longer period between RT and surgery leads to a higher down-staging rate $(44.2 \% \quad$ vs. $13 \%) .{ }^{19}$ Moreover, a $\quad$ Swedish retrospective study reported that $74 \%$ of the patients had tumor regression on MRI after a median of 4 weeks after the completion of RT but it was noticed that only $55.4 \%$ of the patients had MRI reassessment. $^{29}$

In our study the rate of down-staging was $54.1 \%$, It was noticed that patients with $\mathrm{cN} 2$ disease, radiological EMVI, and radiological involved mesorectalfacia (MRF) tend to have a statistically significant worse clinical down-staging.

A Korean study showed a higher conformal radiation dose to the target and significantly reduced the dose to OAR when using short course IMRT compared to the four-box field (3D-CRT), ${ }^{30}$ our study results were consistent regarding PTV coverage and femoral head mean dose but Bowel and bladder mean doses were higher than those reported in the IMRT arm but still better than the conformal radiotherapy results, the difference may be attributed to the utilization of tomotherapy in the Korean study.

In our study, severe early and late toxicity were reported in $5.4 \%$ and $8.1 \%$ of the patients respectively, Polish trial reported that the incidence of severe early and late adverse effects in SCRT arm was $3.2 \%$ and $10.1 \%$ respectively. ${ }^{14}$

Stockholm III trial reportedsevere acute toxicity in $<1 \%$ of the patients receiving SCRT with immediate surgery group, $4.2 \%$ of the patients in SCRT with delayed surgery group and $5 \%$ in the CCRT group, and it was thought that acute radiation toxicity was masked by surgical complications in the SCRT with immediate surgery group. ${ }^{17}$

A retrospective study including patients who received SCRT then delayed surgery, Severe radiation-induced toxicity was reported in $5.4 \%$ of them. $^{29}$

Polish trial demonstrated that the rates of postoperative complications for the SCRT with immediate surgery group and the long course CCRT group were $27 \%$ vs $21 \%$, respectively but it was noticed that only $39 \%$ of the patients had APR. ${ }^{31}$

In an older Dutch trial, it was noticed that patients who had an abdominoperineal resection, after preoperative RT had more perineal complications than those assigned to surgery alone $26 \%$ vs. $18 \%{ }^{32}$

Stockholm III trial showed a significantly lower incidence of postoperative complications in the SCRT followed by delayed surgery vs. SCRT with immediate surgery, (41\% vs. 53\%). ${ }^{17}$

In our study, postoperative complications were reported in $37 \%$ of the patients and it was obvious that most of them had APR.

It is suggested that patients with a pCR might have better DFS and OS. ${ }^{10}$ In our study, we reported a pCR rate of $9 \%$, and it was consistent with the results of a retrospective study held in the Netherlands that found a significantly lower pCR rate in patients treated with SCRT with delayed surgery compared to long course CCRT (9.3\% vs. $17.5 \%$ respectively). ${ }^{\mathbf{1 8}}$ 
Stockholm III trial reported a pCR rate of $11.8 \%$ in patients receiving SCRT with delayed surgery. ${ }^{16}$

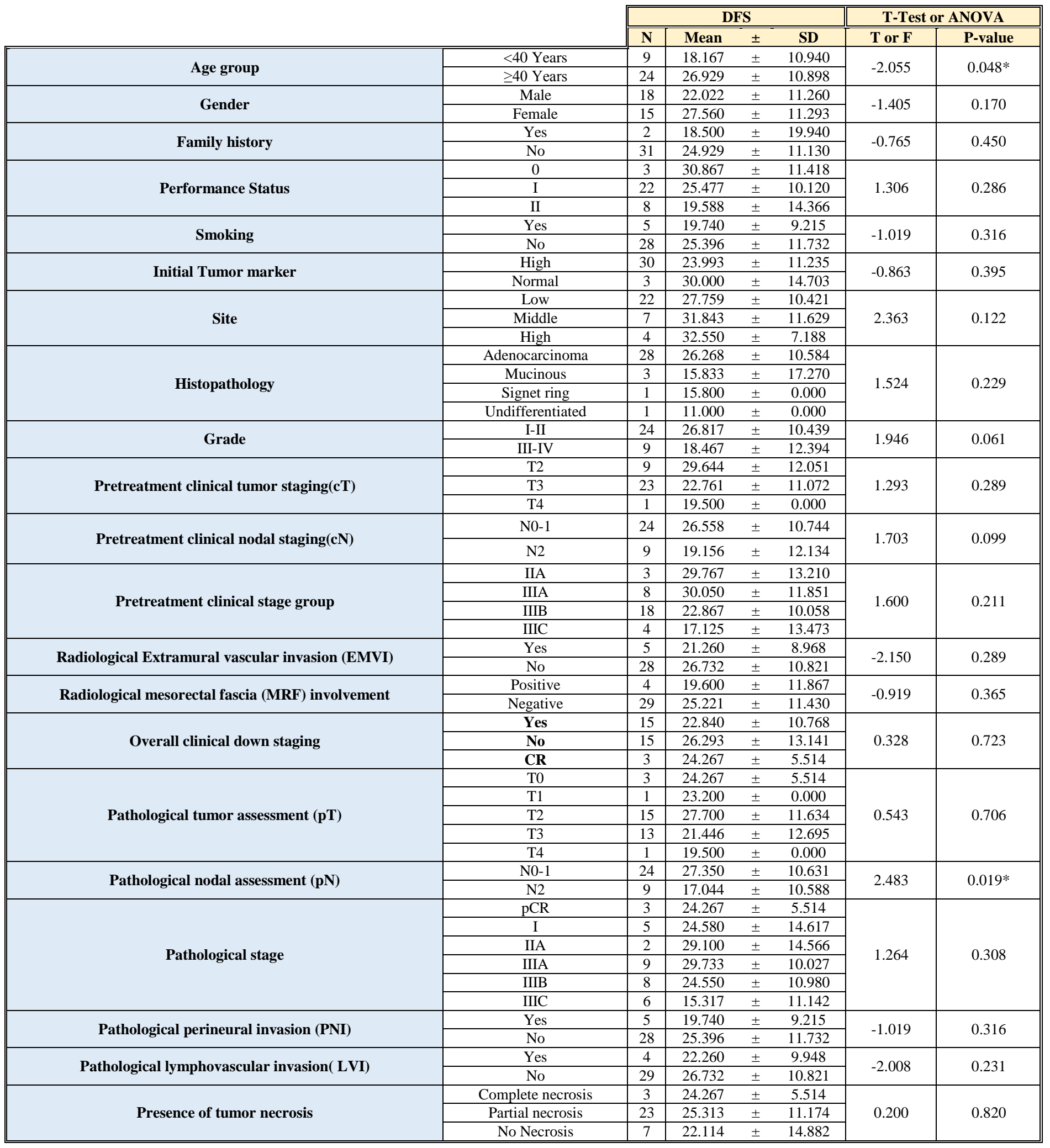

Table 7:Disease free survival and its relation to the prognostic factors. 


\begin{tabular}{|c|c|c|c|c|c|c|c|}
\hline & & \multicolumn{4}{|c|}{ OS } & \multicolumn{2}{|c|}{ T-Test or ANOVA } \\
\hline & & $\mathbf{N}$ & Mean & \pm & SD & T or $\mathbf{F}$ & P-value \\
\hline \multirow{2}{*}{ Age group } & $<40$ Years & 9 & 20.378 & \pm & 9.317 & \multirow{2}{*}{-1.860} & \multirow{2}{*}{0.072} \\
\hline & $\geq 40$ Years & 24 & 27.692 & \pm & 10.309 & & \\
\hline \multirow{2}{*}{ Gender } & Male & 18 & 23.211 & \pm & 10.158 & \multirow{2}{*}{-1.529} & \multirow{2}{*}{0.136} \\
\hline & Female & 15 & 28.680 & \pm & 10.317 & & \\
\hline \multirow{2}{*}{ Family history } & Yes & 2 & 22.100 & \pm & 14.849 & \multirow{2}{*}{-0.497} & \multirow{2}{*}{0.623} \\
\hline & No & 31 & 25.929 & \pm & 10.394 & & \\
\hline \multirow{3}{*}{ Performance Status } & 0 & 3 & 30.867 & \pm & 11.418 & \multirow{3}{*}{1.025} & \multirow{3}{*}{0.371} \\
\hline & I & 22 & 26.459 & \pm & 9.284 & & \\
\hline & II & 8 & 21.663 & \pm & 13.067 & & \\
\hline \multirow{2}{*}{ Smoking } & Yes & 5 & 20.860 & \pm & 9.245 & & \\
\hline & No & 28 & 26.561 & \pm & 10.557 & -1.129 & 0.267 \\
\hline & High & 30 & 25.267 & \pm & 10.164 & & \\
\hline Initial Tumor marker & Normal & 3 & 30.000 & \pm & 14.703 & -0.143 & 0.463 \\
\hline & Low & 22 & 27.141 & \pm & 9.484 & & \\
\hline Site & Middle & 7 & 32.957 & \pm & 10.085 & 4.719 & 0.117 \\
\hline & High & 4 & 32.550 & \pm & 7.188 & & \\
\hline & Adenocarcinoma & 28 & 27.089 & \pm & 9.996 & & \\
\hline & Mucinous & 3 & 18.967 & \pm & 14.526 & & \\
\hline Histopathology & Signet ring & 1 & 17.400 & \pm & 0.000 & 1.144 & 0.348 \\
\hline & Undifferentiated & 1 & 15.200 & \pm & 0.000 & & \\
\hline & I-II & 24 & 26.067 & \pm & 11.844 & & \\
\hline Grade & III-IV & 9 & 20.188 & \pm & 11.446 & 1.276 & 0.301 \\
\hline & $\mathrm{T} 2$ & 9 & 30.511 & \pm & 11.163 & & \\
\hline Pretreatment clinical tumor staging(cT) & T3 & 23 & 24.083 & \pm & 9.967 & 1.447 & 0.251 \\
\hline & $\mathrm{T} 4$ & 1 & 19.500 & \pm & 0.000 & & \\
\hline & N0-1 & 24 & 27.121 & \pm & 10.330 & & \\
\hline Pretreatment clinical nodal staging(cN) & $\mathrm{N} 2$ & 9 & 21.900 & \pm & 10.347 & 1.293 & 0.206 \\
\hline & IIA & 3 & 29.767 & \pm & 13.210 & & \\
\hline & IIIA & 8 & 30.050 & \pm & 11.851 & & \\
\hline Pretreatment clinical stage group & IIIB & 18 & 24.172 & \pm & 9.330 & 1.040 & 0.389 \\
\hline & IIIC & 4 & 20.800 & \pm & 10.615 & & \\
\hline & Yes & 5 & 22.840 & \pm & 6.159 & & \\
\hline Radiological Extramural vascular invasion (EMVI) & No & 28 & 27.279 & \pm & 10.319 & -2.176 & 0.146 \\
\hline 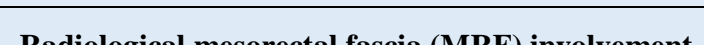 & Positive & 4 & 20.550 & \pm & 10.961 & 1052 & 0200 \\
\hline Radiological mesorectal fascia (MIRF) involvement & Negative & 29 & 26.407 & \pm & 10.365 & -1.053 & 0.300 \\
\hline & Yes & 15 & 23.227 & \pm & 10.418 & & \\
\hline Overall clinical down staging & No & 15 & 28.453 & \pm & 11.011 & 0.969 & 0.391 \\
\hline & Clinical CR & 3 & 24.267 & \pm & 5.514 & & \\
\hline & T0 & 3 & 24.267 & \pm & 5.514 & & \\
\hline & T1 & 1 & 23.200 & \pm & 0.000 & & \\
\hline Pathological primary tumor assessment (ypT) & $\mathrm{T} 2$ & 15 & 28.327 & \pm & 11.102 & 0.445 & 0.775 \\
\hline & T3 & 13 & 23.662 & \pm & 11.159 & & \\
\hline & $\mathrm{T} 4$ & 1 & 19.500 & \pm & 0.000 & & \\
\hline & N0-1 & 24 & 27.650 & \pm & 10.397 & & \\
\hline Pathological nodal assessment (ypN) & $\mathrm{N} 2$ & 9 & 20.489 & \pm & 9.132 & 1.817 & 0.079 \\
\hline & pCR & 3 & 24.267 & \pm & 5.514 & & \\
\hline & $\mathrm{I}$ & 5 & 24.580 & \pm & 14.617 & & \\
\hline & IIA & 2 & 29.100 & \pm & 14.566 & & \\
\hline Pathological stage & IIIA & 9 & 29.911 & \pm & 9.760 & 0.804 & 0.557 \\
\hline & IIIB & 8 & 26.225 & \pm & 9.981 & & \\
\hline & IIIC & 6 & 19.183 & \pm & 9.487 & & \\
\hline & Yes & 5 & 16.840 & \pm & 6.159 & & \\
\hline Pathological perineural invasion (PNI) & No & 28 & 20.860 & \pm & 9.245 & -1.129 & 0.267 \\
\hline & Yes & 4 & 26.561 & \pm & 10.557 & & \\
\hline Pathological lymphovascular invasion( LVI) & No & 29 & 27.279 & \pm & 10.319 & -2.048 & 0.137 \\
\hline & Partial necrosis & 23 & 26.048 & \pm & 10.520 & & \\
\hline Presence of tumor necrosis & No Necrosis & 7 & 25.157 & \pm & 12.798 & 0.047 & 0.954 \\
\hline & Complete necrosis & 3 & 24.267 & \pm & 5.514 & & \\
\hline
\end{tabular}

Table 8: Overall survival and its relation to the prognostic factors. 
Bujko, K., et al., (2004) compared sphincter preservation rates between SCRT with immediate surgery and CCRT with delayed surgery and reported no significant difference, ${ }^{33}$ also there was no difference between SCRT with immediate or delayed surgery. ${ }^{19}$ In our study, the sphincter preservation rate was $52.5 \%$, but for patients who had low rectal tumors, the rate was $28 \%$. Although polish trial, reported a higher sphincter preservation rate of $61 \%$, this can be explained if we know that, they were selecting patients with no clinical evidence of sphincter involvement. ${ }^{33}$

Just 34 years ago, before the era of TME, postoperative RT, with anterior and posterior parallel opposed fields reduced the local recurrence (LR) from $25 \%$ to $16 \%,{ }^{34}$ with TME alone the (LR) rate declined to $11 \%$ and when preoperative CCRT was added further decline to $4.6 \%$ was achieved, patients with low rectal tumors, those with advanced tumor stage, and patients submitted to APR were found to have the highest LR rates. ${ }^{35}$

Dutch trial reported a two years LR rate of $2.4 \%$ in patients treated with SCRT with immediate surgery, but most of the study patients had a low stage (patients with stage < III: $59 \%$ ) and only $27 \%$ of the patients had low rectal tumors. ${ }^{32}$

The Swedish rectal cancer trial eventually reported that the LR rate was $9 \%$ after short-course RT with immediate surgery. ${ }^{36}$

In our study, the rate of LR was $9 \%$, but it was noticed that $66.6 \%$ of the study group had low rectal tumors, and $69.7 \%$ of them had stage III disease.

In our study, the median DFS and OS have not been reached, and the cumulative DFS at 1 year and 2 years were $88 \%$ and $71 \%$ respectively, while the cumulative OS at 1 year and 2 years were $90.1 \%$ and $80 \%$ respectively.

Dutch trial showed an insignificant overall survival difference at two years between pre-operative SCRT with immediate surgery and surgery alone (82\% vs. $81.8 \%)^{32}$

Bujko, K., et al., (2004) compared neoadjuvant CCRT with delayed surgery to SCRT with immediate surgery, and showed no significant difference in survival, the cumulative 4-year overall survival was $66.2 \%$ in the CCRT group vs. $67.2 \%$ in the short-course group, and disease-free survival was $55.6 \%$. Vs. $58.4 \%$ respectively. ${ }^{14}$ A Randomized clinical trial compared SCRT with either immediate or delayed surgery, the 5-year survival was $63 \%$ vs. $73 \%$ but the difference was statistically insignificant, while a statistically significant increase in 5-year survival was noticed in patients who had downstaging after radiotherapy compared to patients who had no response to RT ( $90 \%$ vs. $60 \%$ respectively). ${ }^{19}$

\section{CONCLUSION}

Short-course radiotherapy with delayed surgery is a valid convenient, safe, and economically beneficial option in the management of locally advanced resectable rectal carcinoma, utilization of IMRT can help in reducing the dose to organs at risk. However, more studies with a larger number of patients are mandatory to identify the category of patients who may have the best benefit of this approach and to confirm the potential clinical benefit of using IMRT.

\section{REFERENCES}

1. Sauer R, Liersch T, Merkel S, et al. Preoperative versus postoperative chemoradiotherapy for locally advanced rectal cancer: results of the German CAO/ARO/AIO-94 randomized phase III trial after a median follow-up of 11 years. $J$ ClinOncol. 2012;30(16):1926-33.

2. Song $\mathrm{JH}$, Jeong $\mathrm{JU}$, Lee $\mathrm{JH}$, et al. Preoperative chemoradiotherapy versus postoperative chemoradiotherapy for stage II-III resectable rectal cancer: a meta-analysis of randomized controlled trials. RadiatOncol J. 2017;35(3):198207.

3. Jin F, Luo $\mathrm{H}$, Zhou J, et al. Dose-time fractionation schedules of preoperative radiotherapy and timing to surgery for rectal cancer. TherAdv Med Oncol. 2020;12.

4. Braendengen M, Tveit KM, Berglund A, et al. Randomized phase III study comparing preoperative radiotherapy with chemoradiotherapy in nonresectable rectal cancer. J ClinOncol. 2008;26(22):3687-94.

5. Sebag-Montefiore D, Stephens RJ, Steele R, et al. Preoperative radiotherapy versus selective postoperative chemoradiotherapy in patients with rectal cancer (MRC CR07 and NCIC-CTG C016): a multicentre, randomised trial. Lancet. 2009;373(9666):811-20.

6. Gérard JP, Conroy $\mathrm{T}$, Bonnetain $\mathrm{F}$, et al. Preoperative radiotherapy with or without concurrent fluorouracil and leucovorin in T3-4 rectal cancers: results of FFCD 9203. $J$ ClinOncol. 2006;24(28):4620-5.

7. Bosset JF, Collette L, Calais G, et al. Chemotherapy with preoperative radiotherapy in rectal cancer [published correction appears in $\mathrm{N}$ Engl J Med. 2007 Aug 16;357(7):728]. $N$ Engl J Med. 2006;355(11):1114-23.

8. Hall MD, Schultheiss TE, Smith DD, et al. Effect of increasing radiation dose on pathologic complete response in rectal cancer patients treated with neoadjuvantchemoradiation therapy. ActaOncol. 2016;55(12):1392-9.

9. Maas M, Nelemans PJ, Valentini V, et al. Longterm outcome in patients with a pathological complete response after chemoradiation for rectal cancer: a pooled analysis of individual patient data. Lancet Oncol. 2010;11(9):835-44.

10. Abdel-Rahman O, Kumar A, Kennecke HF, et al. Impact of Duration of Neoadjuvant Radiation on Rectal Cancer Survival: A Real World Multicenter Retrospective Cohort Study. Clin Colorectal Cancer. 2018;17(1):e21-8.

11. David Sebag-Montefiore, Richard J Stephens, Robert Steele, et al.Randomized study on 
preoperative radiotherapy in rectal carcinoma. Stockholm Colorectal Cancer Study Group. Ann SurgOncol. 1996;3(5):423-30.

12. Goldberg PA, Nicholls RJ, Porter $\mathrm{NH}$, et al. Long-term results of a randomised trial of shortcourse low-dose adjuvant pre-operative radiotherapy for rectal cancer: reduction in local treatment failure. Eur $J$ Cancer. 1994;30A(11):1602-6

13. Pettersson D, Cedermark B, Holm T, et al. Interim analysis of the Stockholm III trial of preoperative radiotherapy regimens for rectal cancer. Br J Surg. 2010;97(4):580-7.

14. Bujko K, Nowacki MP, Nasierowska-Guttmejer A, et al. Long-term results of a randomized trial comparing preoperative short-course radiotherapy with preoperative conventionally fractionated chemoradiation for rectal cancer. $\mathrm{Br}$ J Surg. 2006;93(10):1215-23.

15. Ansari N, Solomon MJ, Fisher RJ, et al. Acute Adverse Events and Postoperative Complications in a Randomized Trial of Preoperative Shortcourse Radiotherapy Versus Long-course Chemoradiotherapy for T3 Adenocarcinoma of the Rectum: Trans-Tasman Radiation Oncology Group Trial (TROG 01.04). Ann Surg. 2017;265(5):882-8.

16. Pettersson D, Lörinc E, Holm T, et al. Tumour regression in the randomized Stockholm III Trial of radiotherapy regimens for rectal cancer. $\mathrm{Br} J$ Surg. 2015;102(8):972-8.

doi:10.1002/bjs.9811.

17. Erlandsson J, Holm T, Pettersson D, et al. Optimal fractionation of preoperative radiotherapy and timing to surgery for rectal cancer (Stockholm III): a multicentre, randomised, non-blinded, phase 3, non-inferiority trial. Lancet Oncol. 2017;18(3):336-46.

18. Rombouts AJM, Hugen N, Verhoeven RHA, et al. Tumor response after long interval comparing 5x5Gy radiation therapy with chemoradiation therapy in rectal cancer patients. Eur $J$ SurgOncol. 2018;44(7):1018-24.

19. Pach R, Kulig J, Richter P, et al. Randomized clinical trial on preoperative radiotherapy $25 \mathrm{~Gy}$ in rectal cancer--treatment results at 5-year follow-up [published correction appears in Langenbecks Arch Surg. 2019 Sep;404(Suppl 1):19-20]. Langenbecks Arch Surg. 2012;397(5):801-7.

20. Jacobs BL, Zhang Y, Schroeck FR, et al. Use of advanced treatment technologies among men at low risk of dying from prostate cancer. JAMA. 2013;309(24):2587-95.

21. Chun SG, Hu C, Choy $\mathrm{H}$, et al. Impact of Intensity-Modulated Radiation Therapy Technique for Locally Advanced Non-Small-Cell Lung Cancer: A Secondary Analysis of the NRG Oncology RTOG 0617 Randomized Clinical Trial. J ClinOncol. 2017;35(1):56-62.
22. Yang Y, Feng L, Wang Y, et al. A Dosimetric Analysis of Preoperative Intensity-modulated and Image-guided Radiation Therapy with and without Simultaneous Integrated Boost for Locally Advanced Rectal Cancer. Technol Cancer Res Treat. 2015;14(5):557-63.

23. Edge SB and Compton CC. The American Joint Committee on Cancer: the 7th edition of the AJCC cancer staging manual and the future of TNM. Ann SurgOncol. 2010;17(6):1471-4.

24. Oken MM, Creech RH, Tormey DC, et al. Toxicity and response criteria of the Eastern Cooperative Oncology Group. Am J ClinOncol. 1982; 5(6 ): 649-56.

25. Myerson RJ, Garofalo MC, El Naqa I, et al. Elective clinical target volumes for conformal therapy in anorectal cancer: a radiation therapy oncology group consensus panel contouring atlas. Int $J$ RadiatOncolBiol Phys. 2009;74(3):824-30.

26. Gay HA, Barthold HJ, O'Meara E, et al. Pelvic normal tissue contouring guidelines for radiation therapy: a Radiation Therapy Oncology Group consensus panel atlas [published correction appears in Int J RadiatOncolBiol Phys. 2012 Sep 1;84(1):7]. Int $J$ RadiatOncolBiol Phys. 2012;83(3):e353-62.

27. Cox JD, Stetz J andPajak TF. Toxicity criteria of the Radiation Therapy Oncology Group (RTOG) and the European Organization for Research and Treatment of Cancer (EORTC). Int $J$ RadiatOncolBiol Phys. 1995;31(5):1341-6.

28. Marijnen CA, Nagtegaal ID, Klein Kranenbarg E, et al. No downstaging after short-term preoperative radiotherapy in rectal cancer patients. J ClinOncol. 2001;19(7):1976-84.

29. Pettersson D, Holm T, Iversen $H$, et al. Preoperative short-course radiotherapy with delayed surgery in primary rectal cancer. $\mathrm{Br} J$ Surg. 2012;99(4):577-83.

30. Yu M, Jang HS, Jeon DM, et al. Dosimetric evaluation of Tomotherapy and four-box field conformal radiotherapy in locally advanced rectal cancer. RadiatOncol J. 2013;31(4):252-9.

31. Bujko K, Nowacki MP, Kepka L, et al. Postoperative complications in patients irradiated pre-operatively for rectal cancer: report of a randomised trial comparing short-term radiotherapy vschemoradiation. Colorectal Dis. 2005;7(4):410-6

32. Kapiteijn E, Marijnen CA, Nagtegaal ID, et al. Preoperative radiotherapy combined with total mesorectal excision for resectable rectal cancer. N Engl J Med. 2001;345(9):638-646.

33. Bujko K, Nowacki MP, Nasierowska-Guttmejer A, et al. Sphincter preservation following preoperative radiotherapy for rectal cancer: report of a randomised trial comparing short-term radiotherapy vs. conventionally fractionated radiochemotherapy. RadiotherOncol. 2004;72(1):15-24. 
34. Gastrointestinal Tumor Study Group. Prolongation of the disease-free interval in surgically treated rectal carcinoma. $N$ Engl $J$ Med. 1985;312(23):1465-72.

35. Kusters M, Marijnen CA, van de Velde CJ, et al. Patterns of local recurrence in rectal cancer; a study of the Dutch TME trial. Eur J SurgOncol. 2010;36(5):470-6.

36. Folkesson J, Birgisson H, Pahlman L, et al. Swedish Rectal Cancer Trial: long lasting benefits from radiotherapy on survival and local recurrence rate. J ClinOncol. 2005;23(24):564450 . 